\title{
Mortality of workers on an isopropyl alcohol plant and two MEK dewaxing plants
}

\author{
M R ALDERSON AND N S RATTAN \\ From the Division of Epidemiology, Institute of Cancer Research, Sutton, Surrey SM2 SPX, UK
}

\begin{abstract}
An historical prospective study was undertaken of 262 men who had worked on an isopropyl alcohol plant and 446 men who had worked on two MEK dewaxing plants. All of the former have been traced, and only one man from the latter group was lost to follow-up. These studies linked occupational records with cause of death data for those who had died; the average follow-up was 15.5 years for the IPA plant workers and 13.9 years for those on the MEK dewaxing plants. For the IPA workers the observed deaths (26) were slightly above the expected (23.6), and there was a non-significant excess of deaths from neoplasms $(0=9, \mathrm{E}=6 \cdot 19)$. One person died from nasal cancer $(E=0.02, p=0.017)$; though based on small numbers this finding is unlikely to be due to chance and agrees with the original hazard. For those who had worked on the MEK dewaxing plants the observed deaths (46) were below the expected (55.51) and there was also a slight deficiency of deaths from neoplasms $(0=13, E=14 \cdot 26)$. When the seven sites of malignancy, which had been examined in a recent American study, were compared there were significantly more deaths from buccal cavity and pharynx cancers $(0=2 ; E=0.13 ; p=0.008)$ and significantly fewer from lung cancer $(0=1 ; E=6.02 ; \mathrm{p}<0.045)$. After reviewing the American and present results, it was concluded that there is no clear evidence of a cancer hazard in these workers, though further follow-up of larger numbers is necessary for a more precise estimate of the confidence limits of these findings.
\end{abstract}

The aim of the study was to determine the mortality in workers who have been employed on (1) the IPA plant at Shell Stanlow, and (2) the MEK dewaxing plants at Shell Haven and Shell Stanlow and to check whether there was any excess mortality from malignant disease.

\section{Background}

Weil, Smyth, and Nale ${ }^{1}$ had collected data on a small group of individuals who had worked from the 1930 's until 1950 at a plant manufacturing isopropanol in the USA. Out of all the workers they identified seven neoplasms of the respiratory tract, including four affecting the paranasal sinuses (this was later supplemented by investigation of all records of deaths that had occurred among employees; no further sinus cancers had occurred). In parallel they arranged animal skin testing and identified carcinogenic activity from isopropyl oil.

Enterline $^{2}$ has investigated the pattern of mortality

Received 22 February 1979

Accepted 1 June 1979 of all workers on the isopropyl alcohol plant at Deer Park, USA, from 1943 to 1975 . He followed up 434 men who were known to have worked on this plant, and found a lower overall mortality and malignant disease mortality than would be expected using national and State statistics. There were eight deaths from malignancy when 11.53 were expected. He noted one death from cancer of the buccal cavity and pharynx, however, when only 0.38 were expected; though not statistically significant this was of interest in view of the earlier observations. ${ }^{1}$ It was concluded $^{2}$ that there was no clear evidence from this study that exposure in the manufacture of isopropyl alcohol as carried out at Deer Park produces cancer in man.

In 1975 workers in the lubricants dewaxing unit in the Deer Park, Texas, plant of Shell Chemical Company reported a rise in the cancer incidence among their fellow workers. In 1976 Dr Enterline was asked to carry out a follow-up study to verify this. His report ${ }^{3}$ showed that the overall mortality in the plant was less than expected, and there was no evidence of an excess of malignant disease. In fact only five deaths from malignant disease had occurred 
when 6.04 were expected. Two of these deaths were from prostate cancer; it was pointed out that this could only be considered a suggestive finding, as none of the known chemical exposures to these men were associated with prostate cancer, and an appreciable number of tests of significance had been done on the range of specific malignancies. (This meant that the significance level was difficult to assess.) The final conclusion was that the American study, based on 305 workers, was too small to provide clear evidence of any but the most potent occupational hazard. It was therefore recommended that a continuing follow-up of the cohort was desirable (Shell Chemicals, USA, have confirmed that this will take place).

\section{Plants concerned}

An isopropyl alcohol plant was brought into successful operation at Stanlow in 1949 and, apart from the usual short shutdowns for maintenance, has operated continuously since then. The feed to the plant is a mixture of propane and propylene obtained initially by the pyrolysis of gas oil and after 1952 from the Stanlow catalytic cracker and thermal refiner. Propylene in the feed is converted to isopropyl alcohol by reaction with sulphuric acid, and the residual propane is returned to the refinery. The chemical process is similar to the one in the earlier American study, ${ }^{1}$ though it is not possible to comment on the chemical levels in the work environment.

In 1935 Shell decided to build at Shell Haven its first plant in Britain for manufacturing a full range of high viscosity index lubricating oils (HVI luboil). To prepare low-pour test HVI luboils the oils needed dewaxing as one stage in the process. The dewaxing method selected was Texaco's benzene/ acetone solvent process, but the Shell Group's own US supply of methyl-ethyl ketone (MEK) was used in place of acetone. It remained working with negligible modification until 1971 , when there was a gradual switch from the use of benzene to toluene. In 1972 the plant was shut down and shortly after dismantled. An MEK dewaxing plant was introduced at Shell Stanlow in 1940 as part of the duosol plant (a solvent extraction plant making luboils using propane and cresylic acid solvents); this was shut down in 1957 and later demolished. A new microwax plant with an MEK/benzene solvent deoiling process was introduced in 1962 (to make paraffin wax from waxy distillate); a further MEK dewaxing plant (HVI luboil) was introduced at the end of 1968. Both these plants are still operational. As was the case at Shell Haven, benzene has been replaced by toluene as a solvent.
In the late 1950s flexible manning was introduced at Stanlow, which meant that the personnel records could not identify those men specifically working solely on the IPA or the MEK dewaxing plants. In 1963 there was a brief trial of flexible manning at Shell Haven; in 1966-7 flexible manning was finally introduced, and a shared team worked on the MEK plant and an adjacent plant. (This was the rectiflow plant using furfural extraction for removal of aromatics from luboil by passage through multiple settling chambers.) After 1967 it is impossible to identify which men specifically worked on the MEK plant. In addition the equipment on all these plants would have been serviced by peripatetic maintenance teams; it is not possible to identify these men as they will have moved from plant to plant without a specific location identified in their job history on personnel records.

\section{Method}

In 1976 the Institute of Petroleum funded a general study of mortality at eight refineries in Britain, which is being carried out by the division of epidemiology at the Institute of Cancer Research. This study includes individuals who have worked for a minimum of one year at both Shell Haven and Shell Stanlow. Only limited details are recorded for each individual; in particular, the data on occupation are restricted to the last job (or present job for those still in post). All men, however, who have left the company and whose status was not known have been traced. When the division of epidemiology was invited to carry out the isopropyl alcohol and MEK dewaxing studies it was agreed that the overlap between the Institute of Petroleum study and these specific inquiries would facilitate follow-up of the men on the particular plants.

Shell staff have defined the job terms that identify those men who worked on the relevant plants at Shell Haven and Shell Stanlow. Only men who had worked for a minimum of one continous year on any of the three specific plants have been included in the study. To identify men with the appropriate work history clerical staff in the personnel departments at both refineries then examined the personnel records and read all the occupational histories. As each man was identified a proforma was completed giving the following details: limited identification particulars; date of birth; dates of starting and ceasing work on the specific plant (some men had worked for two or more spells on the plant and the dates for each spell were recorded). It was also noted whether the individual was in the Institute of Petroleum study (the particular difference between the two studies being that men who had left the company before 
1 January 1950 were not included in that study). Each of the men was then classified into one of the following five categories:

(1) In post on 1 January 1976 (the date selected for the initial end of the follow-up).

(2) Died in post.

(3) Retired and known to the pension fund.

(4) Left the company before retirement.

(5) Left the company on retirement, but not known to the pension fund.

For those included in the Institute of Petroleum study, follow-up arrangements had been made to obtain status on 31 December 1975. Where a man's National Health Service number was known he was traced through the National Health Service Central Register (NHSCR); where the National Insurance number was known he was traced through the social security records of the Department of Health and Social Security (DHSS). Where only name, date of birth, and address was known tracing was initially attempted through the NHSCR. If the NHSCR or the DHSS were unable to trace the man the alternative central register was contacted; in addition when there was difficulty in tracing the occupational records were rechecked in the refinery personnel departments to verify the abstraction of the identification particulars. For all those who were found to be dead (either known to have died in post, died as a pensioner, or died on follow-up through the NHSCR or DHSS) the full death details were obtained from the Office of Population Censuses and Surveys. These death details have been used to code the underlying cause of death, using the International Classification of Disease revision prevailing at the time of death.

A unique number was allotted to each man, and his plant history was coded. These particulars together with the date of birth, and dates on and off the plant, date last known alive, and follow-up status were punched and in-put to a computer file. Using a standard computer program (MYCL-an acronym for man years computer language ${ }^{4}$ ) the data were converted to person years at risk by five year agegroup and five year calendar periods. National mortality rates by cause, age, and calendar period were applied to these person years at risk to calculate the expected numbers of deaths. The observed and expected deaths have been compared and their difference tested for significance (where the expected figure is larger than 5 , chi squared has been used, with one degree of freedom; otherwise the data have been treated as a Poisson variable to estimate the probability of obtaining the actual or greater difference than found). The data processing has been checked, initially by verifying the number of records stored on the computer file against a clerical count of the hard-copy records. The basic data in-put for each individual has been subject to an edit check to rule out impossible or inconsistent values. The person years at risk has been calculated using the usual MYCL program but also cross-checked by a separate tabulation program. In addition to these checks a table has been produced showing the number of individuals beginning work on the plants at Shell Haven and Shell Stanlow, tabulated by age at entry and calendar period of entry. These tables have been submitted for checking in the personnel departments at the refineries; the numbers obtained from the computer file have been accepted by the refinery staff as representing the annual recruitment of staff and level of manning on the plants.

\section{Results}

Table 1 shows the status on follow-up of all the men in the study. Of the 262 men who had worked on the

Table 1 Status at 31 December 1975 for 262 men working on IPA plant at Shell Stanlow and 446 men working on MEK dewaxing plants at Shell Haven and Shell Stanlow

\begin{tabular}{lllll}
\hline & Alive & Dead & Emigrated & Lost to follow-up \\
\hline $\begin{array}{l}\text { IPA plant } \\
(\mathrm{n}=262)\end{array}$ & 234 & 26 & 2 & 0 \\
$\begin{array}{l}\text { MEK dewaxing plant } \\
(\mathrm{n}=446)\end{array}$ & 393 & 46 & 6 & 1 \\
\hline
\end{tabular}

isopropyl alcohol plant, all have been traced. Only one of the 446 men who had worked on the MEK dewaxing plants has not been traced. From the identification particulars available in the company records it has been impossible to determine whether or not this man has died since leaving the company. His data have been included in the analysis up until the last known date on which he was alive. This no-trace rate of considerably less than $1 \%$ is very satisfactory and extremely unlikely to influence the results that have been obtained. The eight (two plus six) individuals who emigrated have been included up until the date they left the country.

There were over 4000 person years at risk for those men from the IPA plant, with an average follow-up of 15.5 years for each individual. For the 446 men from the MEK dewaxing plants there was a total person years at risk of over 6000 , with an average follow-up of 13.9 years.

Table 2 shows the observed and expected deaths by cause for men from the IPA plant. There was a very slight excess of deaths from all causes (26 observed against 23.60 expected). This difference is not significant, nor is the slight excess of deaths 
Table 2 Observed and expected deaths by cause, ratio of observed and expected deaths, and probability for men working on IPA plant at Shell Stanlow

\begin{tabular}{lcccc}
\hline Cause & Observed & Expected & O/E & $p$ \\
\hline All causes & 26 & 23.60 & 1.10 & 0.655 \\
All neoplasms & 9 & 6.19 & 1.45 & 0.273 \\
Buccal cavity and pharynx & - & 0.06 & - & 0.942 \\
Stomach, colon, and rectum & 1 & 1.29 & 0.78 & 0.630 \\
Nose and nasal sinuses & 1 & 0.02 & 50.00 & 0.017 \\
Lung and pleura & 2 & 2.57 & 0.78 & 0.526 \\
Bladder & - & 0.18 & - & 0.835 \\
Hodgkin's disease & - & 0.11 & - & 0.896 \\
Leukaemia & - & 0.18 & - & 0.835 \\
Subsequent analysis & & & & \\
$\quad$ Kidneys, suprarenals & 2 & 0.31 & 6.45 & 0.039 \\
Brain, CNS & 2 & 0.12 & 16.67 & 0.007 \\
\hline
\end{tabular}

from all neoplasms (9 observed against $6 \cdot 19$ expected). Several specific sites of malignancy have been examined; the initial selection was based on the sites examined by Enterline. Only one of these showed a significant excess-nose and nasal sinus cancer $(0=1, E=0.02, p=0.017)$. Subsequent examination of the deaths showed two from kidney and suprarenal malignancy and two from neoplasms of the brain and central nervous system; for both of these sites a preliminary test of significance gives values of 0.039 and 0.007 respectively. The ninth death was from cancer of the oesophagus.

Table 3 shows the observed and expected deaths by cause for men from the MEK dewaxing plants.

Table 3 Observed and expected deaths by cause, with ratio of observed and expected deaths and probability values for 446 men working on MEK dewaxing plants at Shell Haven and Shell Stanlow

\begin{tabular}{lccrr}
\hline Cause & Observed & Expected & \multicolumn{1}{c}{$O / E$} & \multicolumn{1}{l}{$p$} \\
\hline All causes & 46 & 55.51 & 0.83 & $<0.206$ \\
All neoplasms & 13 & 14.26 & 0.91 & $<0.752$ \\
Buccal cavity and pharynx & 2 & 0.13 & 15.38 & 0.008 \\
Stomach, colon, and rectum & 4 & 3.18 & 1.28 & 0.393 \\
Lung and pleura & 1 & 6.02 & 0.17 & $<0.045$ \\
Bladder & - & 0.49 & - & 0.613 \\
Prostate & - & 0.47 & - & 0.625 \\
Leukaemia & 1 & 0.35 & 2.86 & 0.395 \\
Hodgkin's disease & - & 0.18 & - & 0.835 \\
\hline
\end{tabular}

For all causes there is a modest deficiency in observed deaths, with a ratio of 0.83 observed to expected deaths. Similarly, there is a very slight deficit in observed deaths from all neoplasms. The specific sites examined were selected in relation to the similar sites examined by Enterline. ${ }^{2}$ There is an excess of buccal cavity and pharynx deaths $(0=2$; $E=0.13 ; p=0.008)$; there was a deficiency of deaths from lung cancer $(0=1 ; E=6.02 ; p<0.045)$. In addition to the eight deaths from malignant neo- plasms shown in the table, there were a further five each from different sites with no suggested excess over expected values.

\section{Discussion}

The standard technique for analysing this class of information has been applied. 5 The use of cause of death has limitations, but the observed causes are being compared with expected numbers based on actual material. No correction for social class or regional variation in mortality has been applied, as there is no clear indication for this in relation to these workers and the causes of death being examined.

\section{ISOPROPYL ALCOHOL PLANT}

For the men who have worked at the Shell Stanlow IPA plant the mortality is about that expected from applying national rates; though there is a very slight apparent excess of neoplasms, this is no greater than one would expect by chance. There were only nine deaths from all neoplasms, and there is great difficulty therefore in examining these deaths by specific site. The earlier reported work from the USA $^{1}$ had indicated that nasal sinus cancer was one possible hazard; a specific examination of observed and expected cancer for this site has been carried out. Though only one observed cancer occurs, the expected figure is so low that this difference is statistically significant $(p<0.02)$. The conclusion is that this result, though based on relatively small numbers of men and only including one nasal cancer, is compatible with there being a real risk of this malignancy. The suggestion from the study is that the men have about a 50 -fold risk of this rather rare cancer. Having stated this, it must be remembered that this contributes only slightly to the overall pattern of mortality among these workers.

On a preliminary test of significance the excess of deaths from kidney and suprarenal neoplasms and brain tumours appears unlikely to be a chance finding. After consideration of the several comparisons made, however, it is unlikely that either of these differences are due to anything other than chance. Due to the small numbers and the number of separate comparisons made, one would expect an occasional result apparently to be significant when it is more a reflection of variability within the data. A pragmatic correction sometimes applied in this situation is to multiply the probability obtained by the number of comparisons made; this would bring the probability of even the neoplasms of the brain and central nervous system above the conventional level of significance of $0 \cdot 05 .^{6}$

Lung cancer is the commonest cause of death from 
malignant disease among men in Britain. The observed deaths among this group of workers are, in fact, lower than the expected figure; this is also the finding among the MEK dewaxing process workers. Smoking is a major cause of lung cancer, and conceivably these refinery workers have a slightly lower cigarette consumption than other men in Britain.

A study based on the follow-up of only 262 men for about 15 years will serve only to identify or exclude a major health hazard. It is suggested that the future mortality patterns of the living members of this cohort be examined, preferably adding data for other men employed on similar work.

\section{MEK DEWAXING PLANTS}

The slight reduction in overall mortality and in mortality from all neoplasms agrees with the findings from the US study. The one specific site of malignancy for which a significant excess of deaths was found in the American study was prostate; there were in fact no deaths from this cause in these $\mathbf{4 4 6}$ Shell UK men, with an expected figure of $0 \cdot 47$. This supports the American conclusion that their finding was due to chance rather than to some specific factor associated with work on a dewaxing plant. (Possibly there are major differences in the working environment between the American and British plants, but this would seem to be a very tenuous line of argument.)

There is one site for which there is a highly significant excess of deaths on initial testing-that is, buccal cavity and pharynx - where two deaths were observed and 0.13 were expected. It is thought that this difference may have occurred by chance remembering the small numbers affected and the number of separate comparisons between observed and expected that have been made. Using the same correction as applied to the IPA results ${ }^{6}$ would bring the probability above the conventional level of significance: $0.008 \times 7=0.056$.

The overall conclusion from this work suggests that the men have a relatively good expectation of life, with no obvious evidence that their mortality from neoplasm is different from the all male mortality from neoplasms in Britain. There is no specific indication of a particular hazard; because of the small numbers, study of the future mortality patterns of the living members of this cohort is warranted-preferably adding data for other men employed on similar work elsewhere.

The deficiency in lung cancer deaths has already been discussed under the IPA plant subsection.

This study was facilitated by the work on the Institute of Petroleum study and we are most grateful to the research fellow Ms L Rushton for help. M R Alderson gratefully acknowledges financial support from the Cancer Research Campaign.

\section{References}

1 Weil CS, Smyth HF, Nale TW. Quest for industrial carcinogen. Arch Indust Hyg 1952;5:535-47.

2 Enterline PE. Cancer in man engaged in manufacture of isopropyl alcohol, Deer Park, Texas, 1941-75. Report to Shell Oil Company, 25 July 1977.

3 Enterline PE. Mortality among workers from Shell Oil Company's lubricants' dewaxing unit at Deer Park, Texas. Report to Shell Oil Company, 25 January 1978.

4 Hill ID. Computing man years at risk. Br J Prev Soc Med $1972 ; 26: 132-4$.

5 Alderson MR. An introduction to epidemiology. London: Macmillan, 1977.

6 Evans CC, Lewinsohn HC, Evans JM. Frequency of HLA antigens in asbestos workers with and without pulmonary fibrosis. Br Med J 1977;1:603-5. 